\title{
EFFECT OF MULTIMODAL STRATEGIES ON THE LEARNING OF LISTENING SKILLS AMONG JUNIOR SECONDARY SCHOOL STUDENTS IN SOKOTO METROPOLIS, SOKOTO STATE, NIGERIA
}

\author{
CHINYERE ONYEBUCHI (Gamji Girls' College, Rabah, Sokoto State, Nigeria) \\ MOHAMMED IBRAHIM (Dept. of Curriculum Studies \& Educational Technology, Usmanu \\ Danfodiyo University, Sokoto, Nigeria)
}

\begin{abstract}
This research investigated the effect of multimodal strategies of teaching listening skills in Junior Secondary Schools in Sokoto metropolis, Sokoto State. The objective was to find out if using multimodal strategies to teach listening skills will enhance their learning when compared to traditional method. The population was 59,265 JSS students in Sokoto Metropolis. Stratified sampling technique was used to select the schools while random sampling technique was used to select one intact class from each school. Thus, the sample size was 394 JSS1 students. The instrument used for collecting data after treatment was Listening Level Test (LLT). Thirty questions were designed with options A, B and C. A group of 10 questions were set relating to each of the listening type: attitudinal, informative and appreciative. The validity of the instrument was determined by some Junior Secondary School English teachers and language education experts in the Department of Curriculum Studies and Educational Technology, Usmanu Danfodiyo University, Sokoto. Pilot study was conducted on twenty students through test-re-tests method to determine the reliability of the study. The results were correlated using Pearson's Product Moment Coefficient formula which produced a reliability index of 0.83. The data collected after administration of the treatment was analyzed using mean, standard deviation to answer the research questions and t-test to test the null hypotheses of the research. It was found that multimodal strategies enhanced the listening comprehension skills of the subjects. The researchers recommended that teachers should use multimodal strategies to teach listening skills in junior secondary schools so as to help students perform very better in listening skills.
\end{abstract}

\section{Introduction}

Language is a gift that can be appreciated from the many facets of use and functions it performs in man's life. Amadi (2001) outlined some of the functions which include: as an instrument of thought, expression of identity, recording of facts, control of reality, creation of imagination and ideas, instrument of social performance among others. Language has four major skills: listening, speaking, reading and writing. The English language is native to the English people while to non- native speakers of English like Nigerians, it is a second language. The non-native speaker of English will have short comings in his/her competence and also in the use of the various skills in the language (Omolewa, 1985). The importance of English language lies in the fact that it is language of government, the mass media, the language of information and also the language instruction (Uba, 1998). Similarly, instructors use English language to teach all subjects in Nigeria school curricular.

Feytin (1991) commented that listening is an integral aspect of a person's over all language ability. Listening skills have types - attitudinal, informative, appreciative and critical /analytical listening. Attitudinal listening involves listening not only to what is said but also determining the attitude of the speaker to the subject matter on hand and the addressee on the other. Informative listening covers a wide range of information that makes up the import of the discourse. The listener at this level should be able to differentiate between facts and opinion in the aural discourse to be able to respond appropriately to issues raised therein. Appreciative listening involves not only listening to what has been said but also to the aesthetics involved in the message. While critical / analytic listening demands on the listener to go beyond the aural text 
to evoke his / her experiential background to make meaning from what has been said. It is pertinent to stress here that not all learners are the same in evoking the use these various listening when dealing with daily demand for communication. Therefore, it becomes imperative that language teachers should pay special attention in developing the listening skills among their learners.

The need for a language teacher to vary his/her method of lesson delivery cannot be over emphasized. This is because not all learners learn the same way. Each student in a classroom has a unique and complex system of thinking and learning. Effective teachers want to know better ways to reach their learners, thus, they have to use effective plan of action so that students will learn easily. Solutions might best be found by combing the best teaching models - multimodal strategies inclusive instead of a one-size-fits-all approach. Multimodal strategy is a style in which learners learn through a number of different sensory modes. Hence, a teacher should be able to create a learning environment in which students learn through auditory and visual methods, or visual and tactile methods. The combination of modes a teacher makes is not really an issue so long as it is appropriate and combines more than one mode. Multimodal strategies if properly implemented ensure students understand and retain information. Multimodal strategies also appeal to all learning style, therefore, can be used to break monotony in lesson presentation and thereby reinforce overall learning. Thomson (2005) maintained that often teachers found their students talking and chatting among others and do not concentrate on the listening subject. Teachers should be able to use multimodal strategies to keep their students focused.

\section{Statement of the Problem}

Over the years, there has been correlation between teachers' ability to teach properly during lessons and learners' ability to perform brilliantly in their academic work (Kelley, 1974). One of the most neglected English language skills, and any other language for that matter, in most Nigeria secondary schools, particularly at the secondary school level, is listening. These writers' experiences as secondary school teachers and language teacher trainer have shown that some teachers thought that there is no need to teach listening skills as a topic in the school timetable. It is a natural fact that when students are taught listening skills very well, they would be in good position to make recalls and respond positively to questions. This is so because, in most Nigerian public schools, teachers use direct method of teaching which draws extensively from students' ability to listen effectively for learning to take place. The researchers are of the opinion that poor performance and lack of interest shown by teachers to teach listening skills and subsequently learners' inability to listen effectively may be factors that contribute significantly to students' learning difficulties in English and other subject areas. When learners are not taught to listen well, they will not have full comprehension and therefore fail in their academic performance. This study sees multimodal strategies of teaching as a strategy that could enhance the learning of listening skills.

\section{Objective of the Study}

The overall objective of this research was to find out the effect of using multimodal strategies to teach listening skills in junior secondary school (JSS1) in Sokoto metropolis, Sokoto States. Specifically the objectives of the research were: 
To examine whether using multimodal strategies to teach learners Attitudinal listening will make them perform better than using Traditional method.

To ascertain if learners who are taught informative listening using multimodal strategies differ in listening performance from those who were taught using traditional method.

To examine whether using multimodal strategies to teach learners appreciative listening will make students perform better than using Traditional method.

\section{Research Questions}

Three research questions were formulated for the research:

Is there any difference in the listening performance of learners taught Attitudinal listening using multimodal strategies and those taught using Traditional method?

Is there any difference in the listening performance of learners taught Informative listening using multimodal strategies and those taught using Traditional method?

Is there any difference in the listening performance of learners taught Appreciative listening using multimodal strategies and those taught using Traditional method?

\section{Research Hypotheses}

In the course of this research, three null hypotheses were formulated tested:

There is no significant difference in the post-test mean scores of experimental groups taught Attitudinal Listening using Multimodal Strategies and control groups taught the same skill using Traditional Method.

There is no significant difference in the post-test mean scores of the experimental groups taught Informative Listening using Multimodal Strategies and control groups taught using Traditional Method.

There is no significant difference in the post-test mean scores of experimental groups taught Appreciative Listening using Multimodal Strategies and control groups taught using Traditional Method.

Previously, efforts have been made in using disc, radio and television to help learners grasp what they are being taught by scholars. For example, Hossein (2013) made an effort in using audio films to improve the listening comprehension in students and it yielded a good result. These efforts are related to this work in the sense that multimodal strategy was used which involve more than one mode. Other available research findings have pointed to the efficacy of presenting lesson in more than one mode in improving students learning. For example, Ibrahim (2013) investigated the effectiveness of video presentation techniques (VPT) on the learning of grammatical structures among senior secondary school students of Sokoto State, Nigeria using senior secondary II students. The objective was to find out whether presentation of grammar lessons in form of video activities would promote the learning of Noun, Adjectival and Adverbial Phrases among the subjects. Quasi-experimental pre-testposttest design where six groups were compared after pre-test, treatment and posttest was used in carrying out the research. Statistical procedures of mean, standard deviation, t-test and Analysis of Variance (ANOVA) were used in testing the four hypotheses of the research The findings of the study showed that the treatments of video presentations of grammar lessons received by the experimental groups were 
superior to the traditional methods treatment received by the control groups thus confirming that a multi-modal approach particularly via video helped improved the learning of grammatical structures among the subjects.

Similarly, Ibrahim (2014) investigated the use of video presentation techniques (VPT) and the use of grammatical structures among senior secondary school students of Sokoto State, Nigeria using A sample of 400 SS I students were drawn from six senior secondary schools in the State. The main objective was to find out whether the secondary school students would use noun, adjectival and adverbial phrases in the right contexts if grammar lessons were presented in form of video activities. Quasiexperimental pre-test-post-test design where six groups were compared after pre-test, treatment was used in carrying out the research. Each of the grammatical structures noun, adjectival and adverbial phrases - was presented to each of the experimental groups in series of lessons. Grammar Application Test was administered on both the experimental and control groups as pre-test and post-test. Four null hypotheses were tested at 0.05 level of significance using mean, standard deviation, t-test and Analysis of Variance (ANOVA) as statistics procedures. All the four null hypotheses were rejected. The findings of the study showed that students in the experimental groups who received lessons in video activities were able to use the grammatical structures learned in the correct context better than those in control groups who received instructions in traditional method.

Bao (2016) on the other hand investigated the teaching of listening at a university in Inner Mongolian with the objective of comparing traditional listening teaching mode, which only uses audio resources, with multimodal self-directed teaching mode as well as examining learners' acceptance to the multimodal teaching mode and its teaching effect. The researcher used questionnaires and tests, as well as discussing the effects multimodal self-directed listening teaching has on learners' listening level and multiliteracy ability. His findings suggests that multimodal teaching mode was popular with most of the students. Similarly, he found that it can help effectively improve learners self-directed learning and effectively enhance listeners' listening level and multi-literacy ability.

\section{Methodology}

The research design used for the study was quasi experimental pre-test post test design to examine the effect of Multimodal Strategies of teaching and learning listening skills among Junior Secondary School in Sokoto Metropolis of Sokoto State. The design was used because the researchers agreed with other scholars' opinion that true experimental research might not be possible where so many human factors cannot be brought under control. The researchers used four homogeneously equal groups where three groups served as experimental and one served as a control. Each of the three listening skills under investigation was taught to one of the experimental groups. The same allocation was made in the control group.

The target population for the study was 10,206 JSS 1 students, both boys and girls in Junior Secondary Schools within Sokoto Metropolis. The students were considered homogeneous because they had just been promoted to JSS class after completing their primary education. Random sample technique was used to select four Junior Secondary Schools and one intact class from each school to participate in the study. 
The sample size was three hundred and ninety four (394). Random sampling technique was used to assign treatment to each class.

\section{Instrumentation}

The data for the research were collected by means of Listening Level Test (LLT) which was adapted. Thirty questions which contained dialogues, sentences, statement and questions were attached to each item with three options A,B \& C to test students' listening level in Attitudinal, Informational and Appreciative listening. Ten questions were set relating to each of the listening type. The instrument was validated by experts in the Department of Curriculum Studies and Educational Technology UDUS for critical evaluation. Their evaluation ascertained that the instrument possessed both face and content validity. In establishing the reliability of the instrument, test re-test technique was used where Pearson Product Moment Co-efficient was used to correlate the results and reliability index of 0.83 was realized.

\section{Data Analysis and Results}

Mean, standard deviation and t-test were the main statistics employed to answer the research questions and to determine rejection of the hypotheses or otherwise. The results are presented in Tales 1-3 according to research questions.

Research questions 1: Is there any difference in the listening performance of learners taught Attitudinal listening using multimodal strategies and those taught using Traditional Method?

Table 1: T-test Posttest for Control and Experimental Groups in Attitudinal Listening

\begin{tabular}{llllllll}
\hline Attitudinal Variables & $\mathrm{N}$ & Mean & SD & DF & t-cal & P-value & Decision \\
\hline Experimental Group & 67 & 17.58 & 1.79 & & & & \\
& & & & 145 & 25.42 & 0.00 & Rejected \\
Control Group & 80 & 9.93 & 1.84 & & & & \\
\hline Alphat & & & & & &
\end{tabular}

Alpha value $=0.05$

Table 1 presents the posttest of both experimental and control groups after treatment. The gains in performance shows that the experimental group recorded main gain with mean score of 17.58 as compared to 9.93 of the control group. Therefore, the answer to the research question shows that there is difference between experimental group and control with the former performing better than the latter. The t-test confirmed that the observed difference is significant as the calculated of 25.42 was found significant when the critical value of 0.00 was compared to alpha value of 0.05 leading to the rejection of the null hypothesis which stated that there is no significance difference in the post-test mean scores of experimental groups taught Attitudinal Listening using multimodal strategies and control groups taught using Traditional method. Thus one could conclude that the difference was as a result of the treatment given to the experimental group by a way of multimodal treatment.

Research questions 2: Is there any difference in the listening performance of learners taught Informative listening using multimodal strategies and those taught using Traditional method? 
Table 2: $\quad$ T-test for difference between control and experimental groups in informative listening

\begin{tabular}{lccccccc}
\hline $\begin{array}{l}\text { Informative Listening } \\
\text { Variables }\end{array}$ & $\mathrm{N}$ & Mean & $\mathrm{SD}$ & $\mathrm{DF}$ & $\mathrm{t}$-cal & P-value & Decision \\
\hline Experimental Group & 50 & 17.60 & 1.62 & & & & \\
& 50 & 9.40 & 1.82 & & & & \\
Control Group & & & & & & & \\
\hline Alpha value $=0.05$ & & & & & &
\end{tabular}

Table 2 presents the posttest of control and experimental groups on informative listening. The table shows the mean scores of the experimental and control groups were 17.60 and 9.40 respectively. The standard deviation of experimental group was 1.62 while that of the control group was 1.82 . The calculated t value was 23.83 with p-value of 0.00 . When compared to alpha value of 0.05 the $\mathrm{p}$-value was not high enough to accept the null hypothesis. Hypothesis two which states that there is no significant difference in the post-test mean scores of the experimental groups taught using multimodal strategies and control groups taught using Traditional method in Informative Listening was thus rejected. It was concluded that there is significance difference in the listening performance of students taught using multimodal strategies and those taught using traditional methods with the experimental group showing superiority.

Research Questions 3: Is there any difference in the listening performance of learners taught Appreciative Listening using multimodal strategies and those taught using Traditional Method?

Table 3: T-test of Posttest of Control and Experimental Groups in Appreciative Listening

\begin{tabular}{lccccccc}
\hline $\begin{array}{l}\text { Appreciative Listening } \\
\text { Variables }\end{array}$ & $\mathrm{N}$ & Mean & SD & DF & t-cal & P-value & Decision \\
\hline Experimental Group & 50 & 17.48 & 1.61 & & & & \\
& & & & 145 & 25.41 & 0.00 & Rejected \\
Control Group & 97 & 9.55 & 1.88 & & & & \\
\hline
\end{tabular}

Alpha value $=0.05$

Table 3 presents the performance of the experimental and control groups in Appreciative listening after treatment. The table reveals that calculated the mean score of the experimental group was 17.48 with a standard deviation of 1.61 . The control group on the other hand recorded a mean score of 9.55 with a standard deviation of 1.88. The calculated t value of 25.41 with $p$-value of 0.00 was found significant to reject the null hypothesis 3 at 0.05 alpha level of significance. Hypothesis three states that, there is no significant difference in the post-test mean scores of experimental groups taught using multimodal strategies and control groups taught using Traditional method in Appreciative Listening. Base on this result, it was concluded that there is significance difference in the listening performance of those students in the experimental class who show superiority over those in the control class. 


\section{Summary of the Major Findings}

The analyses above revealed the following findings:

The students taught using multimodal techniques performed better than the students in the control group who did not receive multimodal supplement showing a significant mean difference of 7.65 .

Also the students in the experimental groups showed better performance in Informative Listening with a significant mean difference of 8.2.

Similarly, the students in experimental group outperformed those in control in Appreciative Listening with a significant mean difference of 7.93.

\section{Discussion of Findings}

The finding of this study in respect of hypothesis one is in agreement with Ibrahim (2013), Ibrahim (2014) and Dopemu (2011). Their findings showed that the students who were exposed to experimental class exposed to multimodal treatment made more or higher gains than those students who were not. In case of Ibrahim (2013), he found that his subjects assisted with multimodal treatment learnt grammatical concepts better than the control group who were not. While a similar finding in Ibrahim (2014) showed that students who were assisted with multimodal supplement in communication setting were able to use grammatical structures in the right context. The finding of the also consistent with the findings of Boa (2016) who reported the use of multimodal technique superior to the traditional method of using audio input only in teaching listening.

The findings of this study also confirmed the findings of Chandrika (2011) and Hosseins (2013). For example Chandrika found that Audio Visual Presentation technique helped his subject in the acquisition of second language listening skills at high school level. Husseins on the other hand found that the using of audio films improved the listening comprehension of the Iranian students. The findings equally agree with Tather (2011) whose finding revealed that audio visual programs can be utilized as pedagogically valuable authentic source of language input for language learning. The finding shows that students perform better when audio visual strategy is applied especially in language learning.

\section{Conclusion}

Based on the findings of the present study, it was found that multimodal strategies can enhance the listening comprehension skills by helping learners arouse their background knowledge or create new schemas. Again, the significantly higher mean scores of the experimental groups not only suggests that lively scenes can improve listening skills scores, but also verifies that multimodal strategy is more satisfactory for listening skills than traditional method alone. The use of multimodal strategies promoted cognitive gain and increase students listening performance. It was discovered that students' attitude during the experimental class was positive. Lastly, the use of multimodal strategies for teaching and learning listening skills could lead to higher listening achievement than the use of traditional approach could instill in the students the spirit of enquiry and problem solving if well utilized. 


\section{Recommendation}

Base on the findings of the study the following recommendations were made:

Teachers should try to use the multimodal strategies in teaching Attitudinal listening skills in junior secondary schools so as to help students become active listener so as to perform better in the class.

Teachers should use multimodal strategies in teaching Informative listening in our various junior secondary schools as this will make students to stay focused as lessons goes on.

Similarly, teacher should be multimodal in presenting appreciative listening lesson in other to provide favourable learning environment for them to develop the skill.

Since doing all these require availability of relevant instructional aids, relevant authorities should ensure that they provide listening teachers enough learning aids that will enable them to employ multimodal strategies in lesson presentation 


\section{References}

Amadi, R. N. (Ed) (2001). Language Education issues and Insights. Owerri Barloz Publishers.

Bao, X. L. (2016). A Research on Multimodal Self-Directed English Listening Teaching Model. Canadian Social Science, 12 (6): 80-86. Available from: http://www.cscanada.net/index.php/css/article/view/8589 DOI: http://dx.doi.org/10.3968/8589.

Chandrika, M. (2011). Impact of AVP technique in the acquisition of second language listening skills at high school level. An unpublished thesis submitted to Bharathiar University, Coimbatore.

Dopemu, E. A. (2010). Effect of teaching listening and speaking skills using audio visual materials on students' oral English performance in senior secondary schools in senior Secondary Schools in Kano State. An unpublished thesis for the award of master Degree in education, Curriculum and instruction. Ahmadu Bello University Zaria, Nigeria.

Feytin, C. (1991). The power of listening ability an overlooked dimension in language acquisition. The modern language Journal, 75 (2): 173-180

Hossein, N. F. (2013). The effect of using audio films on improving listening comprehension. A dissertation submitted to English department, faculty of humanities, 1k International University, Qazvin, Iran.

Ibrahim, M. (2013).The Effectiveness of Video Presentation Techniques on Learning of Grammatical Structures among Senior Secondary School Students in Sokoto State, Nigeria, Journal of Education and Practice, 4 (16).

Ibrahim, M. (2014).Video Presentation Technique and the Use of Some Grammatical Structures among Senior Secondary Students in Sokoto State, Nigeria, Sky Journal of Educational Research, 2 (6): 047 - 052

Omolewa, M. (1985) The English language in colonial Nigeria. 1860-1992 A study of the major factors that promoted the language journal of the Nigeria English Studies Association.

Tather, B. (2011). Audiovisual news, cartoons and films as sources of authentic language input and language proficiency enhancement. An unpublished dissertation submitted to faculty of language and linguistics, University of Malaya, Malaysia.

Thomson, K. (2005). BBC British Council: Helping teen to listen. http/www.teahingenglish.org.uk/think/listen/teen.shtml. (assessed at 4th October, 2007).

Uba, E. C. (1998). A Handbook on English Language and Literature in the Secondary schools. Owerri: Diocese printing press. 